\title{
Management of Male Breast Cancer: The Journey so Far and Future Directions
}

\author{
Quratulain (Anna) Sabih ${ }^{\mathrm{a}}$, Jessica Young ${ }^{\mathrm{a}}$, Kazuaki Takabe a, b, c, d, e, f, g
}

\begin{abstract}
Male breast cancer is now shown to be a unique entity and should be considered as a distinct disease. Given the relatively smaller number of cases, randomized controlled trials for treatment are extremely limited and majority of practices are derived from female breast cancer studies. This paper reviews available literature on surgical, radiation, and systemic therapies for male breast cancer, and discusses current practice recommendations.
\end{abstract}

Keywords: Male; Male breast cancer; Breast cancer in men; Treatment

\section{Introduction}

Breast cancer is conventionally thought of as a disease of women, but the reality is that male breast cancer $(\mathrm{MaBC}) \mathrm{ac}-$ counts for approximately $1 \%$ of all breast cancer diagnosis worldwide [1-5]. This number is not insignificant when we consider that breast cancer has now overtaken lung cancer as the most commonly diagnosed cancer in women according to GLOBOCAN, an international body calculation of the global cancer burden [6]. The incidence of $\mathrm{MaBC}$ seems to be increasing over the last few decades [7,8], as seen in the

Manuscript submitted September 28, 2021, accepted November 26, 2021

Published online December 8, 2021

aDepartment of Surgical Oncology, Roswell Park Comprehensive Cancer Center, Buffalo, NY 14263, USA

${ }^{b}$ Department of Surgery, University at Buffalo Jacobs School of Medicine and Biomedical Sciences, the State University of New York, Buffalo, NY, USA

'Department of Breast Surgery and Oncology, Tokyo Medical University, Tokyo 160-8402 Japan

${ }^{\mathrm{d}}$ Department of Gastroenterological Surgery, Yokohama City University School of Medicine, Yokohama 236-004, Japan

eDepartment of Surgery, Niigata University Graduate School of Medical and Dental Sciences, Niigata 951-8510 Japan

fDepartment of Breast Surgery, Fukushima Medical University, Fukushima, Japan

'Corresponding Author: Kazuaki Takabe, Department of Surgical Oncology, Roswell Park Comprehensive Cancer Center, Elm \& Carlton Streets, Buffalo, NY 14263, USA. Email: Kazuaki.Takabe@RoswellPark.org

doi: https://doi.org/10.14740/wjon1418
Surveillance Epidemiology and End Results (SEER) database over the last three decades $[1,9]$. Approximately 500 men are expected to die this year due to MaBC in the USA alone [1, 10].The earliest publication for $\mathrm{MaBC}$ dates to the 1930s and the interest in this unique malignancy has only increased over time. Over 50 thousand publications can be found related to $\mathrm{MaBC}$ on our most recent query (Fig. 1).

$\mathrm{MaBC}$ differs from female breast cancer (FBC) in a variety of ways $[3,9]$. MaBC commonly presents at an older age [11], and lobular cancer is rare [4]. MaBCs are more likely to be estrogen receptor (ER)-positive $[2,5,11,12]$ and less likely to overexpress human epidermal growth factor receptor 2 (Her2) [13] thus luminal subtype is more common [5, 14]. BRCA2 mutations are more common in MaBC compared with $\mathrm{FBC}[2,4,11]$. MaBC has increased incidence of lymph node and distant metastases [11], thus has increased mortality compared to $\mathrm{FBC}$ even after adjusting for attributes like race, ethnicity, access to care or clinical characteristics [15].

Given the relatively small number of cases, management recommendations for $\mathrm{MaBC}$ are deduced from data on $\mathrm{FBC}$ or based on small single institute retrospective studies or on expert opinions and case reports $[1,5,16]$. Only very limited number of clinical trials are conducted on $\mathrm{MaBC}$; thus, it is thought that a narrative summary of management of MaBC will be useful for practicing oncologists. In this paper we will review the current treatment modalities used for $\mathrm{MaBC}$ and current discussions on them.

Table 1 gives an overview of the available therapies available for $\mathrm{MaBC}$.

\section{Surgery}

\section{Lumpectomy vs. mastectomy}

Given the rarity of the disease, there are no randomized clinical trials for MaBC. Observational studies as well as pooled data have been used as guides to decide the surgical options for local control of MaBC. The natural evolution of the management of FBC has been to minimize the extent of operation given the multitude of adjuvant and neoadjuvant systemic therapies available. The National Surgical Adjuvant Breast and Bowel Project (NSABP) trial in 1970s took us from the Halstedian radical mastectomy to modified radical mastectomy $[17,18]$. NASABP B-06 trial in the 1990s made lumpectomy, also known as breast conserving surgery that re- 


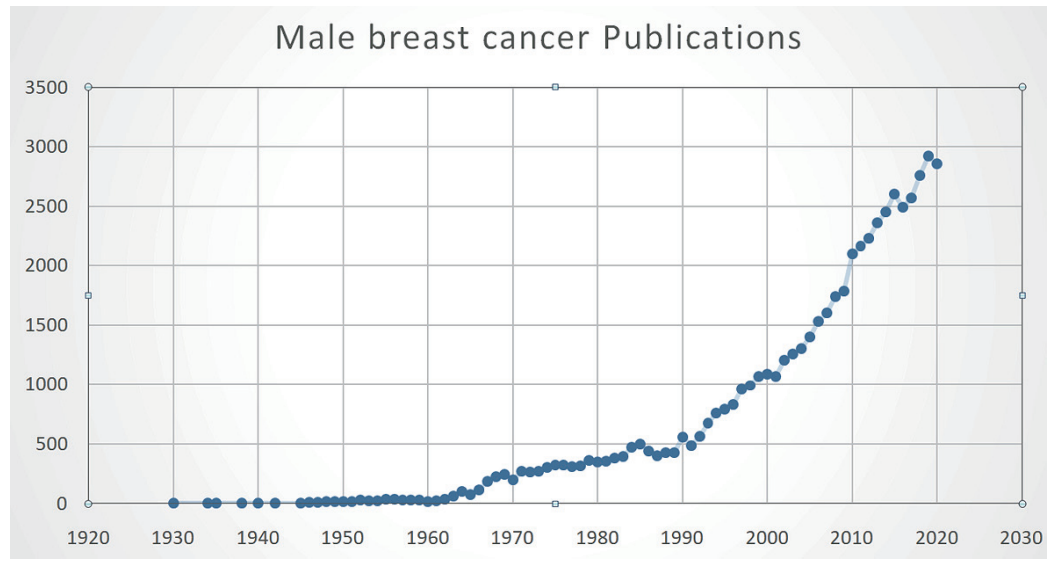

Figure 1. Publication trend for MaBC. MaBC: male breast cancer.

move only the tumor and surrounding tissue leaving majority of breast remaining, a viable and desirable option for female patients [19]. One of the larger observational studies by Fields et al showed that clinical outcomes after lumpectomy with radiotherapy (breast conserving therapy) were not inferior to mastectomy in FBC [20]. Zaenger et al published a SEERbased database analysis in 2016 that showed similar survival after lumpectomy and mastectomy [21]. On the other hand, it needs to be noted that lumpectomy has never been demonstrated to be superior to mastectomy even for FBC other than observational study [22].

Whether lumpectomy is as good an option as total mastectomy in men has been debated over the last few years after adjuvant radiation became a standard of care for smaller lesions being treated with lumpectomy as the breast-conserving therapy (BCT) [23]. Seventeen percent of early stage MaBC patients underwent lumpectomy between 1998 and 2011 according to SEER database [21]. French study by Cutuli et al reviewed $489 \mathrm{MaBC}$ patients in 2009 and found that only $8.9 \%$ underwent lumpectomy [24]. Roswell Park Comprehensive
Cancer Center analysis of 78 patients between the years 1990 and 2015 , showed more conservative numbers for lumpectomy closer to $5 \%$ [25].

Lumpectomy is a smaller surgery and is feasible for early stage MaBC; however, follow-up mammograms may be challenging for men with minimal amount of tissue [25]. Since most MaBCs present with retroareolar lesions, are diagnosed at a later stage, and with aggressive biology, modified radical mastectomy has been considered the standard operation. MaBC lesions are also close to the nipple if not retroareolar, making nipple sparing surgery difficult. The question then remains, are we pushing the envelope when choosing BCT over mastectomy for MaBC $[20,25,26]$. Surgical options for MaBC patient need to be individualized, weighing psychological burden and plastic considerations on top of survival benefits. Mainstay of operation remains mastectomy currently [20, 25, 26].

Surprisingly, analyses of the North American Association of Central Cancer Registries database between the years 2004 - 2011 found that increasing number of MaBC patients were not only choosing modified radical mastectomy for the af-

Table 1. Overview of the Available Therapies Available for MaBC

\begin{tabular}{lll}
\hline Surgery & $\begin{array}{l}\text { Lumpectomy: feasible for very early disease and } \\
\text { disease distant from the nipple-areolar complex } \\
\text { Mastectomy: Most common surgery for MaBC }\end{array}$ & $\begin{array}{l}\text { Surgery should be individualized but current } \\
\text { mainstay of therapy is still mastectomy }\end{array}$ \\
Surgery for axilla & $\begin{array}{l}\text { Clinically negative lymph nodes should be } \\
\text { assessed with sentinel lymph node biopsy } \\
\text { Clinically positive lymph nodes can be biopsied radiographically }\end{array}$ & $\begin{array}{l}\text { Lymph node staging is an integral step for therapy } \\
\text { planning and completed based on clinical exam }\end{array}$ \\
Radiation therapy & Adjuvant radiation therapy is recommended for stage I - III MaBC & $\begin{array}{l}\text { Radiation oncology evaluation should be } \\
\text { considered for all MaBC patients }\end{array}$ \\
Hormonal therapy & $\begin{array}{l}\text { Tamoxifen: hormone-positive MaBC are recommended tamoxifen } \\
\text { for 5 years with option to increase duration to 10 years }\end{array}$ & $\begin{array}{l}\text { Majority of MaBC patients are candidates } \\
\text { for hormone therapy with compliance } \\
\text { being the biggest stumbling block }\end{array}$ \\
& $\begin{array}{l}\text { Aromatase inhibitors: prescribed in the recurrent of metastatic } \\
\text { Cytotoxic chemotherapy has established role in MaBC }\end{array}$ & $\begin{array}{l}\text { Chemotherapy is used in the adjuvant, } \\
\text { neoadjuvant and palliative setting for MaBC }\end{array}$ \\
\hline targeted therapy & $\begin{array}{l}\text { Trastuzumab for HER-2-positive patients can be } \\
\text { exploited for additional survival benefit }\end{array}$ &
\end{tabular}


fected side, but were also opting for prophylactic mastectomy of the contra-lateral side [27]. As matter of fact, the number of patients undergoing contralateral prophylactic mastectomy increased from $3 \%$ to $5.6 \%$ showing an almost $87 \%$ increase [27]. The reasons were thought to be due to increased availability of genetic testing, magnetic resonance imaging (MRI) imaging, and/or the fear of development of breast cancer in the other side.

\section{Management of the axillary lymph nodes in MaBC}

Evaluation of lymph node involvement is essential to determine the stage of the disease and further managements of breast cancer. For clinically negative nodes, i.e., non-palpable, normal size and appearance by imaging, the feasibility and success of sentinel lymph node biopsy (SLNBX) for MaBC is equal to that for women by experienced surgeons [28-30]. SLNBX has been shown to be a reliable alternative to axillary lymph node dissection for evaluation of lymph node metastasis in MaBC $[31,32]$. However, MaBCs are typically diagnosed at a later stage, thus are more likely to be associated with clinically positive lymph nodes, which would require further assessment with fine-needle aspiration or biopsy [32, 33]. If the nodes are clinically positive, it would be more likely for the patient to require an axillary dissection or down staging with neoadjuvant therapy.

\section{Radiation Therapy}

\section{Radiation is more effective in MaBC}

Here we review multiple population studies that investigated whether adjuvant radiation is effective for $\mathrm{MaBC}$ using pooled data. There was no significant benefit by adjuvant radiation in men with higher stage, lymph node involvement and larger tumor size cancers; regardless of type of operation for local control in 1,337 MaBC patients diagnosed between years 1983 and 2002 in SEER database [4]. On the other hand, a near identical analysis of SEER database of 1933 MaBC patients diagnosed between 1998 and 2013, showed significantly improved survival with adjuvant radiation particularly in mastectomy patients with lymph node metastasis [2]. More recently, analysis of National Cancer Database that included 10,873 stage I - III MaBC demonstrated significantly improved survival with adjuvant radiotherapy in stage I MaBC, which was better than that of stage I FBC $[11,34]$. These studies suggest that adjuvant radiation is effective for $\mathrm{MaBC}$.

Gennari et al with the European Institute of Oncology recommended a more aggressive adjuvant radiation therapy for $\mathrm{MaBC}$ greater than $1 \mathrm{~cm}$ or for any patient with positive lymph nodes [35]. The basis of this was the purported ease of chest wall spread given the smaller volume of the male breast [3537]. These recommendations for aggressive radiation therapy should be weighed against increased cardiovascular and pulmonary risks associated with the increased radiation dose [38, 39].

\section{Systemic Therapy}

\section{Tamoxifen}

Breast cancer subtypes determined by biomarker expression (ER, progesterone receptor, and Her2) are essential to classify the disease because it determines the treatment approach [4042]. The near universal expression of ER in MaBC has made this an effective target for therapy $[43,44]$. Eighty percent of estrogen in men is derived from peripheral conversion and $20 \%$ is secreted directly from the testicles [45]. Counter intuitively, men seem to have higher concentrations of estrogen than postmenopausal women $[46,47]$.

Tamoxifen has been proven to be an effective adjuvant endocrine therapy for FBC since the late 1970s. A retrospective analysis of a single institute over a 40 year period showed a marked increase in use of tamoxifen starting in the 1980s [13]. The earliest report on the use of tamoxifen for $\mathrm{MaBC}$ was described by Ribeiro et al in 1992 [12]. Even in these early trials, 1 - 2 years of adjuvant tamoxifen demonstrated a marked improvement in 5-year disease-free survival for stage II and III MaBC $[12,48]$.

A recent prospective German trial that analyzed 316 ERpositive $\mathrm{MaBC}$ found that the rate of recurrence and death were worse in patients who did not receive adjuvant tamoxifen (22\% vs. $14 \%)$ with median follow-up of 39 months [48-50]. Interestingly, tamoxifen consistently showed improved outcomes when compared to aromatase inhibitor (AI), which will be discussed further in the next section $[24,46]$. Tamoxifen is now the recommended first-line systemic endocrine therapy in both adjuvant and palliative setting for $\mathrm{MaBC}$, given improved disease-free and overall survival [9, 44, 48-52]. Surprisingly, it has been reported that one-third of $\mathrm{MaBC}$ qualifying for tamoxifen was never prescribed the drug [15]. Studies are underway to understand this discordant prescription pattern.

Overtime, the recommendation for the duration of tamoxifen has changed. Patients with $\mathrm{MaBC}$ who qualify for adjuvant endocrine therapy are recommended to take tamoxifen for 5 years initially with option to increase duration to 10 years based on established prognostic factors $[16,53]$. Tamoxifen is also associated with poor compliance given its adverse effects and may be due to its long duration $[11,54]$. Side effects include decrease in libido, hot flashes, deep vein thrombosis, mood alterations, depression and sleep disorders [55]. There are reports of rate of attrition for tamoxifen in men being close to $20 \%$ whereas it is much lower in $\mathrm{FBC}$ patients $[54,55]$.

\section{AIs}

Review of available data shows an inconsistent and even discouraging result of $\mathrm{AI}$ for $\mathrm{MaBC}$ [52]. AIs target peripheral conversion of androgens into estrogen, whereas tamoxifen is a competitive ER inhibitor that blocks estrogen signaling. AIs are commonly prescribed to postmenopausal breast cancer patients as opposed to premenopausal patients because the rate of peripheral conversion increases with advancing age, whereas majority of circulating estrogen is supplied by ovary in pre- 
menopausal women. Studies have demonstrated that older men have higher peripheral conversion compared to older women $[46,47]$. Given that men do not have ovaries, it was felt that AI may have stronger effect on $\mathrm{MaBC}$ than tamoxifen. However, this was not shown to be the case $[24,46]$.

Aminoglutethimide, an on-selective AI was studied for $\mathrm{MaBC}[56]$. Among five metastatic $\mathrm{MaBC}$ patients randomized to receive aminoglutethimide, only two showed partial response [56] An English study reviewed five advanced MaBC patients who underwent aminoglutethimide therapy. Only one patient with prior orchiectomy showed partial response and the remaining four without orchiectomy failed to show any response [57].

Anastrozole, a selective AI, is one of the most used endocrine therapies for postmenopausal FBC [58-61]. Giordano et al reported that among five ER-positive MaBC who were treated with anastrozole, three patients showed disease stabilization and two showed marked improvement; however, none of the patients achieved complete response [62]. MD Anderson Cancer Center published their experience of anastrozole for five ER-positive metastatic MaBC patients that showed only marginal efficacy with no case of disease regression $[1,16]$.

Given these disappointing clinical outcomes, the mechanism to explain why AIs were not effective in $\mathrm{MaBC}$ was investigated. The reason appears to be the ineffective suppression of estrogen by AIs [49,63]. AIs reduce the amount of circulating estradiol, the bioavailable form of estrogen, to half through blocking peripheral conversion [64]. This lower estradiol level blocks the hypothalamus-pituitary negative feedback loop, causing an upsurge of luteinizing hormone (LH), follicle-stimulating hormone ( $\mathrm{FSH})$, and then testosterone that ultimately leads to conversion to estrogen [45, 64].

Surgical or chemical castration would be the next logical step to prevent this upsurge. However, addition of gonadotrophin-releasing hormone ( $\mathrm{GnRH})$ modulating drugs that effectively causes chemical castration in addition to AIs only show modest benefit [62]. Zagouri et al investigated the benefits of AIs either as monotherapy or when given along with GnRH modulating drugs as first- or second-line therapy for metastatic $\mathrm{MaBC}$ and found only a quarter of the patients achieved partial response [65]. The addition of GnRH to AIs did not improve disease-free or overall survival of metastatic MaBC $[65,66]$. On the other hand, an Italian study that reviewed $60 \mathrm{MaBC}$ in a pooled data showed modest benefits of combination therapy; with improvements seen in response rates (51\% vs. $43 \%)$, in median progression-free survival (11 months vs. 6 months) and 2-year survival (64\% vs. 43\%) [66, 67].

One German prospective study compared adjuvant AI vs. tamoxifen in MaBC. A total of 257 patients were included in this study with a median follow-up of 42 months. Results showed a 1.5-fold decrease in mortality with the use of tamoxifen as compared to AI $[49,68]$. To this end, AIs are currently offered only for advanced, recurrent or metastatic disease in men by American Society of Clinical Oncology (ASCO) recommendations [16].

\section{Cytotoxic chemotherapy and targeted therapy}

Cytotoxic chemotherapy has been the mainstay for neoadju- vant $[69,70]$ and adjuvant therapy [71] as well as for metastatic breast cancer. A retrospective review of $512 \mathrm{MaBC}$ patients in the SEER database showed that patients with larger tumor size (between 2 and $5 \mathrm{~cm}$ ) and positive lymph nodes were more likely to receive chemotherapy and/or targeted therapy [72]. Interestingly, men who were unmarried or were over the age of 70 were less likely to undergo chemotherapy [72]. It is speculated that this may be due to side effect profile of therapeutic drugs, advanced disease at time of presentation and limited prognosis, concerns on compliance, and lack of social and psychological support.

Breast cancers that overexpress HER2 are known to have highly aggressive biology with aneuploidy, high cell proliferation rate, increased tumor size, likelihood of lymph node metastasis, and tendency to metastasize to the brain $[73,74]$. However, trastuzumab, a HER2-targeted therapy, has revolutionized its management leading to death of cells overexpressing HER2 [74, 75]. There are only anecdotal data and case reports on trastuzumab for MaBC; however, HER2 overexpressing metastatic MaBC did show partial response for a limited duration of time $[13,16,74,76,77]$. There is increasing interest in combination of trastuzumab with anastrozole for advanced $\mathrm{MaBC}$ patients, where combination therapy showing $20 \%$ response rate vs. $7 \%$ with monotherapy with trastuzumab alone [76, 78]. National Comprehensive Cancer Network (NCCN) and ASCO have both recommended considering trastuzumab for high-risk HER2-positive MaBC [16, 74, 79].

\section{Future Directions}

At this time, resources and guidance for MaBC are extrapolated from FBC studies. Consensus committees which include NCCN and ASCO have made recommendations based on case series, review of pooled data or anecdotal experience of physicians treating $\mathrm{MaBC}[16,79]$. Thus, additional research utilizing $\mathrm{MaBC}$ data is needed to further clarify the therapy options.

Genomic tests such as Oncotype DX ${ }^{\mathrm{TM}}$ or Mammaprint ${ }^{\mathrm{TM}}$ are now standard of care to identify which FBC benefits from adjuvant chemotherapy. MaBC was shown to have higher Oncotype DX recurrent score earlier in the disease compared with FBC [44]. Similarly, MaBC with recurrence score more than 31 did more poorly when compared with women with the same score [80]. Recurrence score is highly predictive of mortality for MaBC and also at a much lower score of 21 [81], which raises an argument for wider application of Oncotype DX to enable oncologists to intervene earlier for MaBC [44, 80]. But the urge to incorporate Oncotype DX should be tempered in node-positive MaBC patients, and axillary staging or dissection should be a bigger consideration when considering chemotherapy. Lastly, we have learned a lot in the past few years regarding the benefit of systemic chemotherapy in postmenopausal women with breast cancer. The benefit is not uniform and the adoption of biological signatures such as the Oncotype Dx has made this clear. Even among node-positive postmenopausal women with breast cancer the Oncotype Dx assay demonstrates that most of these women do not benefit from systemic chemotherapy. It is likely that similar biological 
behavior can be expected in MaBC which is usually ER+ and Her2 negative. In women with ER+ breast cancer, pathologic complete response rates are only $4 \%$ for luminal A tumors and $12 \%$ for luminal B tumors. Thus, the putative benefit of preoperative neoadjuvant chemotherapy in $\mathrm{MaBC}$ is likely nil and considerations regarding the use of any systemic chemotherapy should be held until the completion of adequate axillary nodal staging with sentinel node biopsy or axillary dissection in node-positive patients after Oncotype Dx assessment.

$\mathrm{MaBC}$ is a rare condition to begin with but should always invoke the potential for a $B R C A$ predisposition. However not all $\mathrm{MaBC}$ is associated with a documented $B R C A$ predisposition and sporadic cases should be identified as such. To date there are no other genetic mutations significantly associated with MaBC. $\mathrm{MaBC}$ is also associated with node-positive axillary metastasis but little data can be quoted to establish whether this is a biological feature or more likely the result of delay in diagnosis due to its rarity. Even among $B R C A$ male carriers the penetrance of the gene is only $6 \%$ in $B R C A 2$ carriers while in $B R C A 1$ kindred the penetrance is only $1 \%$. Thus, prophylactic bilateral mastectomy in the setting of BRCA1 male carriers should be strongly discouraged since majority of these operations would be of no value and the attendant risk of surgical complications particularly when reconstruction is added to mastectomy in women has been reported to be as high as $14 \%$. Flap necrosis and implant infections can be seriously consequential. The same can be said for $B R C A 2$ male carriers where risk reduction strategies such as a limited course of tamoxifen can halve this risk as shown in women. Interestingly just like $B R C A 2$ mutation purports an increased risk of ovarian cancers in females, men with known $B R C A 2$ mutations should be screened for prostate cancers. While contralateral breast cancer is rare in MaBC patients with $B R C A 2$ mutations, there is a five-fold increase in the risk of prostate cancer relative to sporadic prostate cancer, which supports the screening for prostate cancer in MaBC patients.

Despite all the advances and improvements there is a lag in the survival benefit for MaBC as compared to FBC. Studies show excess mortality of close to $60 \%$ when compared to women [15]. A large registry-based database analysis revealed that combination of continued application of FBC-based therapies and underutilization of adjuvant therapies especially tamoxifen result in overall higher mortality in $\mathrm{MaBC}[15,54]$. Based on the work of organizations like Male Breast Cancer Coalition and International Male breast Cancer Program, a concerted effort is being made to include men along with women in all clinical trials $[16,53]$. Treating this cancer as a unique entity and allowing it to have a seat at the table for clinical trials is the future.

\section{Acknowledgments}

None to declare.

\section{Financial Disclosure}

This research was supported by National Institutes of
Health, USA grant number R01CA160688, R37CA248018, R01CA250412, 1R01CA251545, as well as US Department of Defense BCRP grant number W81XWH-19-1-0674, W81XWH-19-1-0111, as well as Avelas Biosciences grant number AVB620-C-002 to K.T. Roswell Park Comprehensive Cancer Center is supported by NCI/NIH grant P30-CA016056.

\section{Conflict of Interest}

None to declare.

\section{Author Contributions}

Conceptualization: Quratulain (Anna) Sabih and Kazuaki Takabe. Writing-original draft preparation: Quratulain(Anna) Sabih. Writing-review and editing: Quratulain (Anna) Sabih and Kazuaki Takabe. Supervision: Kazuaki Takabe and Jessica Young. Project administration: Kazuaki Takabe. All authors have read and agreed to the published version of the manuscript.

\section{Data Availability}

The authors declare that data supporting the findings of this study are available within the article.

\section{Abbreviations}

FBC: female breast cancer; MaBC: male breast cancer; BCT: breast conservation therapy; SEER: Surveillance Epidemiology and End Results; ASCO: American Society of Clinical Oncology; MRM: modified radical mastectomy; CPM: contralateral prophylactic mastectomy; NCCN: National Comprehensive Cancer Network; AI: aromatase inhibitors; LH: luteinizing hormone; FSH: follicle-stimulating hormone

\section{References}

1. Giordano SH. Breast cancer in men. N Engl J Med. 2018;378(24):2311-2320.

2. Abrams MJ, Koffer PP, Wazer DE, Hepel JT. Postmastectomy radiation therapy is associated with improved survival in node-positive male breast cancer: a population analysis. Int J Radiat Oncol Biol Phys. 2017;98(2):384391.

3. Fentiman IS. Male breast cancer is not congruent with the female disease. Crit Rev Oncol Hematol. 2016;101:119124.

4. Madden NA, Macdonald OK, Call JA, Schomas DA, Lee CM, Patel S. Radiotherapy and male breast cancer: a population-based registry analysis. Am J Clin Oncol. 2016;39(5):458-462.

5. Gucalp A, Traina TA, Eisner JR, Parker JS, Selitsky SR, 
Park BH, Elias AD, et al. Male breast cancer: a disease distinct from female breast cancer. Breast Cancer Res Treat. 2019;173(1):37-48.

6. Sung H, Ferlay J, Siegel RL, Laversanne M, Soerjomataram I, Jemal A, Bray F. Global cancer statistics 2020: GLOBOCAN estimates of incidence and mortality worldwide for 36 cancers in 185 countries. CA Cancer J Clin. 2021;71(3):209-249.

7. Reddington R, Galer M, Hagedorn A, Liu P, Barrack $\mathrm{S}$, Husain E, Sharma R, et al. Incidence of male breast cancer in Scotland over a twenty-five-year period (19922017). Eur J Surg Oncol. 2020;46(8):1546-1550.

8. Speirs V, Shaaban AM. The rising incidence of male breast cancer. Breast Cancer Res Treat. 2009;115(2):429430.

9. Leon-Ferre RA, Giridhar KV, Hieken TJ, Mutter RW, Couch FJ, Jimenez RE, Hawse JR, et al. A contemporary review of male breast cancer: current evidence and unanswered questions. Cancer Metastasis Rev. 2018;37(4):599-614.

10. Siegel RL, Miller KD, Jemal A. Cancer statistics, 2018. CA Cancer J Clin. 2018;68(1):7-30.

11. Yadav S, Karam D, Bin Riaz I, Xie H, Durani U, Duma N, Giridhar KV, et al. Male breast cancer in the United States: Treatment patterns and prognostic factors in the 21st century. Cancer. 2020;126(1):26-36.

12. Ribeiro G, Swindell R. Adjuvant tamoxifen for male breast cancer (MBC). Br J Cancer. 1992;65(2):252-254.

13. Rudlowski C, Rath W, Becker AJ, Wiestler OD, Buttner R. Trastuzumab and breast cancer. N Engl J Med. 2001;345(13):997-998.

14. Johansson I, Nilsson C, Berglund P, Strand C, Jonsson $\mathrm{G}$, Staaf J, Ringner $\mathrm{M}$, et al. High-resolution genomic profiling of male breast cancer reveals differences hidden behind the similarities with female breast cancer. Breast Cancer Res Treat. 2011;129(3):747-760.

15. Wang F, Shu X, Meszoely I, Pal T, Mayer IA, Yu Z, Zheng W, et al. Overall Mortality After Diagnosis of Breast Cancer in Men vs Women. JAMA Oncol. 2019;5(11):15891596.

16. Hassett MJ, Somerfield MR, Baker ER, Cardoso F, Kansal KJ, Kwait DC, Plichta JK, et al. Management of male breast cancer: ASCO guideline. J Clin Oncol. 2020;38(16):1849-1863.

17. Fisher B, Jeong JH, Anderson S, Bryant J, Fisher ER, Wolmark N. Twenty-five-year follow-up of a randomized trial comparing radical mastectomy, total mastectomy, and total mastectomy followed by irradiation. N Engl J Med. 2002;347(8):567-575.

18. Osborne MP. William Stewart Halsted: his life and contributions to surgery. Lancet Oncol. 2007;8(3):256-265.

19. Fisher B, Anderson S. Conservative surgery for the management of invasive and noninvasive carcinoma of the breast: NSABP trials. National Surgical Adjuvant Breast and Bowel Project. World J Surg. 1994;18(1):63-69.

20. Fields EC, DeWitt P, Fisher CM, Rabinovitch R. Management of male breast cancer in the United States: a surveillance, epidemiology and end results analysis. Int J Radiat Oncol Biol Phys. 2013;87(4):747-752.
21. Zaenger D, Rabatic BM, Dasher B, Mourad WF. Is breast conserving therapy a safe modality for early-stage male breast cancer? Clin Breast Cancer. 2016;16(2):101-104.

22. de Boniface J, Szulkin R, Johansson ALV. Survival After Breast Conservation vs Mastectomy Adjusted for Comorbidity and Socioeconomic Status: A Swedish National 6-Year Follow-up of 48986 Women. JAMA Surg. 2021;156(7):628-637.

23. Fisher ER, Anderson S, Redmond C, Fisher B. Ipsilateral breast tumor recurrence and survival following lumpectomy and irradiation: pathological findings from NSABP protocol B-06. Semin Surg Oncol. 1992;8(3):161-166.

24. Cutuli B, Le-Nir CC, Serin D, Kirova Y, Gaci Z, Lemanski C, De Lafontan B, et al. Male breast cancer. Evolution of treatment and prognostic factors. Analysis of 489 cases. Crit Rev Oncol Hematol. 2010;73(3):246-254.

25. Takabe K. Breast-conserving surgery should not be recommended to men with early-stage breast cancer simply because we can perform these operations. HemOnc Today. 2016;17(12):13.

26. Fentiman IS. Surgical options for male breast cancer. Breast Cancer Res Treat. 2018;172(3):539-544.

27. Jemal A, Lin CC, DeSantis C, Sineshaw H, Freedman RA. Temporal trends in and factors associated with contralateral prophylactic mastectomy among US men with breast cancer. JAMA Surg. 2015;150(12):1192-1194.

28. Port ER, Fey JV, Cody HS, 3rd, Borgen PI. Sentinel lymph node biopsy in patients with male breast carcinoma. Cancer. 2001;91(2):319-323.

29. Agrawal A, Ayantunde AA, Rampaul R, Robertson JF. Male breast cancer: a review of clinical management. Breast Cancer Res Treat. 2007;103(1):11-21.

30. Cimmino VM, Degnim AC, Sabel MS, Diehl KM, Newman LA, Chang AE. Efficacy of sentinel lymph node biopsy in male breast cancer. J Surg Oncol. 2004;86(2):7477.

31. Albo D, Ames FC, Hunt KK, Ross MI, Singletary SE, Kuerer HM. Evaluation of lymph node status in male breast cancer patients: a role for sentinel lymph node biopsy. Breast Cancer Res Treat. 2003;77(1):9-14.

32. Boughey JC, Bedrosian I, Meric-Bernstam F, Ross MI, Kuerer HM, Akins JS, Giordano SH, et al. Comparative analysis of sentinel lymph node operation in male and female breast cancer patients. J Am Coll Surg. 2006;203(4):475-480.

33. Chen L, Chantra PK, Larsen LH, Barton P, Rohitopakarn M, Zhu EQ, Bassett LW. Imaging characteristics of malignant lesions of the male breast. Radiographics. 2006;26(4):993-1006.

34. Early Breast Cancer Trialists' Collaborative G, Darby S, McGale P, Correa C, Taylor C, Arriagada R, Clarke M, et al. Effect of radiotherapy after breast-conserving surgery on 10-year recurrence and 15-year breast cancer death: meta-analysis of individual patient data for 10,801 women in 17 randomised trials. Lancet. 2011;378(9804):17071716.

35. Gennari R, Curigliano G, Jereczek-Fossa BA, Zurrida S, Renne G, Intra M, Galimberti V, et al. Male breast cancer: a special therapeutic problem. Anything new? (Review). 
Int J Oncol. 2004;24(3):663-670.

36. Eggemann H, Ignatov A, Stabenow R, von Minckwitz G, Rohl FW, Hass P, Costa SD. Male breast cancer: 20-year survival data for post-mastectomy radiotherapy. Breast Care (Basel). 2013;8(4):270-275.

37. Jardel P, Vignot S, Cutuli B, Creisson A, Vass S, Barranger E, Thariat J. Should Adjuvant radiation therapy be systematically proposed for male breast cancer? A systematic review. Anticancer Res. 2018;38(1):23-31.

38. Czene K, Bergqvist J, Hall P, Bergh J. How to treat male breast cancer. Breast. 2007;16(Suppl 2):S147-154.

39. Hooning MJ, Botma A, Aleman BM, Baaijens MH, Bartelink $\mathrm{H}$, Klijn JG, Taylor CW, et al. Long-term risk of cardiovascular disease in 10-year survivors of breast cancer. J Natl Cancer Inst. 2007;99(5):365-375.

40. Adeniji AA, Dawodu OO, Habeebu MY, Oyekan AO, Bashir MA, Martin MG, Keshinro SO, et al. Distribution of breast cancer subtypes among nigerian women and correlation to the risk factors and clinicopathological characteristics. World J Oncol. 2020;11(4):165-172.

41. Macari A, Soberanis-Pina P, Varela-Santoyo E, ValleSanchez MA, Leal-Hidalgo JL, Torres-Guillen VM, Motola-Kuba D, et al. Prevalence and molecular profile of breast carcinoma using immunohistochemistry markers in Mexican women. World J Oncol. 2021;12(4):119-123.

42. Copeland J, Oyedeji A, Powell N, Cherian CJ, Tokumaru Y, Murthy V, Takabe K, et al. Breast Cancer in Jamaica: Stage, Grade and Molecular Subtype Distributions Across Age Blocks, the Implications for Screening and Treatment. World J Oncol. 2021;12(4):93-103.

43. Humphries MP, Sundara Rajan S, Honarpisheh H, Cserni G, Dent J, Fulford L, Jordan LB, et al. Characterisation of male breast cancer: a descriptive biomarker study from a large patient series. Sci Rep. 2017;7:45293.

44. Fox S, Speirs V, Shaaban AM. Male breast cancer: an update. Virchows Arch. 2021

45. Cardoso F, Bartlett JMS, Slaets L, van Deurzen CHM, van Leeuwen-Stok E, Porter P, Linderholm B, et al. Characterization of male breast cancer: results of the EORTC 10085/TBCRC/BIG/NABCG International Male Breast Cancer Program. Ann Oncol. 2018;29(2):405-417.

46. Khan MH, Allerton R, Pettit L. Hormone therapy for breast cancer in men. Clin Breast Cancer. 2015;15(4):245250.

47. Hemsell DL, Grodin JM, Brenner PF, Siiteri PK, MacDonald PC. Plasma precursors of estrogen. II. Correlation of the extent of conversion of plasma androstenedione to estrone with age. J Clin Endocrinol Metab. 1974;38(3):476-479.

48. Ribeiro G. Male breast carcinoma - a review of 301 cases from the Christie Hospital \& Holt Radium Institute, Manchester. Br J Cancer. 1985;51(1):115-119.

49. Eggemann H, Brucker C, Schrauder M, Thill M, Flock F, Reinisch M, Costa SD, et al. Survival benefit of tamoxifen in male breast cancer: prospective cohort analysis. Br J Cancer. 2020;123(1):33-37.

50. Goss PE, Reid C, Pintilie M, Lim R, Miller N. Male breast carcinoma: a review of 229 patients who presented to the Princess Margaret Hospital during 40 years: 1955-1996.
Cancer. 1999;85(3):629-639.

51. Korde LA, Zujewski JA, Kamin L, Giordano S, Domchek $\mathrm{S}$, Anderson WF, Bartlett JM, et al. Multidisciplinary meeting on male breast cancer: summary and research recommendations. J Clin Oncol. 2010;28(12):2114-2122.

52. Hayes T. Pharmacotherapy for male breast cancer. Expert Opin Pharmacother. 2002;3(6):701-708.

53. Corti C, Crimini E, Criscitiello C, Trapani D, Curigliano G. Adjuvant treatment of early male breast cancer. Curr Opin Oncol. 2020;32(6):594-602.

54. Xu S, Yang Y, Tao W, Song Y, Chen Y, Ren Y, Liu J, et al. Tamoxifen adherence and its relationship to mortality in 116 men with breast cancer. Breast Cancer Res Treat. 2012;136(2):495-502.

55. Anelli TF, Anelli A, Tran KN, Lebwohl DE, Borgen PI. Tamoxifen administration is associated with a high rate of treatment-limiting symptoms in male breast cancer patients. Cancer. 1994;74(1):74-77.

56. Lopez M, Di Lauro L, Lazzaro B, Papaldo P. Hormonal treatment of disseminated male breast cancer. Oncology. 1985;42(6):345-349.

57. Harris AL, Dowsett M, Stuart-Harris R, Smith IE. Role of aminoglutethimide in male breast cancer. Br J Cancer. 1986;54(4):657-660.

58. Higa GM, alKhouri N. Anastrozole: a selective aromatase inhibitor for the treatment of breast cancer. Am J Health Syst Pharm. 1998;55(5):445-452.

59. Wiseman LR, Adkins JC. Anastrozole. A review of its use in the management of postmenopausal women with advanced breast cancer. Drugs Aging. 1998;13(4):321-332.

60. Lonning PE. Aromatase inhibitors and their future role in post-menopausal women with early breast cancer. Br J Cancer. 1998;78(Suppl 4):12-15.

61. Mokbel K. Focus on anastrozole and breast cancer. Curr Med Res Opin. 2003;19(8):683-688.

62. Giordano SH, Valero V, Buzdar AU, Hortobagyi GN. Efficacy of anastrozole in male breast cancer. Am J Clin Oncol. 2002;25(3):235-237.

63. Volm MD. Male breast cancer. Curr Treat Options Oncol. 2003;4(2):159-164.

64. Mauras N, O'Brien KO, Klein KO, Hayes V. Estrogen suppression in males: metabolic effects. J Clin Endocrinol Metab. 2000;85(7):2370-2377.

65. Zagouri F, Sergentanis TN, Koutoulidis V, Sparber C, Steger GG, Dubsky P, Zografos GC, et al. Aromatase inhibitors with or without gonadotropin-releasing hormone analogue in metastatic male breast cancer: a case series. Br J Cancer. 2013;108(11):2259-2263.

66. Hong JH, Ha KS, Jung YH, Won HS, An HJ, Lee GJ, Kang D, et al. Clinical features of male breast cancer: experiences from seven institutions over 20 years. Cancer Res Treat. 2016;48(4):1389-1398.

67. Di Lauro L, Pizzuti L, Barba M, Sergi D, Sperduti I, Mottolese M, Amoreo CA, et al. Role of gonadotropinreleasing hormone analogues in metastatic male breast cancer: results from a pooled analysis. J Hematol Oncol. 2015;8:53

68. Eggemann H, Ignatov A, Smith BJ, Altmann U, von Minckwitz G, Rohl FW, Jahn M, et al. Adjuvant therapy 
with tamoxifen compared to aromatase inhibitors for 257 male breast cancer patients. Breast Cancer Res Treat. 2013;137(2):465-470.

69. Asaoka M, Gandhi S, Ishikawa T, Takabe K. Neoadjuvant Chemotherapy for Breast Cancer: Past, Present, and Future. Breast Cancer (Auckl). 2020;14:1178223420980377.

70. Kin T, Ohtani S, Maeda R, Ueno A, Fujihara M, Takamatsu Y, Kajiwara Y, et al. Nab-paclitaxel followed by 5-fluorouracil, epirubicin and cyclophosphamide in neoadjuvant chemotherapy for resectable breast cancer: a phase ii trial. World J Oncol. 2020;11(5):197-203.

71. Vaid AK, Khurana A, Sharma D, Gautam D, Wadhwa J, Agarwal R, Kaur K, et al. Clinical characteristics and outcome trends of adjuvant anthracycline and Taxane regimen for early stage breast cancer. World J Oncol. 2020;11(3):106-111.

72. Harlan LC, Zujewski JA, Goodman MT, Stevens JL. Breast cancer in men in the United States: a populationbased study of diagnosis, treatment, and survival. Cancer. 2010;116(15):3558-3568.

73. Uberall I, Kolar Z, Trojanec R, Berkovcova J, Hajduch $M$. The status and role of ErbB receptors in human cancer. Exp Mol Pathol. 2008;84(2):79-89.

74. Ottini L, Capalbo C, Rizzolo P, Silvestri V, Bronte G, Rizzo S, Russo A. HER2-positive male breast cancer: an update. Breast Cancer (Dove Med Press). 2010;2:45-58.

75. Spector NL, Blackwell KL. Understanding the mechanisms behind trastuzumab therapy for human epidermal growth factor receptor 2-positive breast cancer. J Clin
Oncol. 2009;27(34):5838-5847.

76. Carmona-Bayonas A. Potential benefit of maintenance trastuzumab and anastrozole therapy in male advanced breast cancer. Breast. 2007;16(3):323-325.

77. Hayashi H, Kimura M, Yoshimoto N, Tsuzuki M, Tsunoda N, Fujita T, Yamashita T, et al. A case of HER2positive male breast cancer with lung metastases showing a good response to trastuzumab and paclitaxel treatment. Breast Cancer. 2009;16(2):136-140.

78. Kaufman B, Mackey JR, Clemens MR, Bapsy PP, Vaid A, Wardley A, Tjulandin S, et al. Trastuzumab plus anastrozole versus anastrozole alone for the treatment of postmenopausal women with human epidermal growth factor receptor 2-positive, hormone receptor-positive metastatic breast cancer: results from the randomized phase III TAnDEM study. J Clin Oncol. 2009;27(33):5529-5537.

79. Gradishar WJ, Anderson BO, Abraham J, Aft R, Agnese $\mathrm{D}$, Allison KH, Blair SL, et al. Breast Cancer, Version 3.2020, NCCN clinical practice guidelines in oncology. J Natl Compr Canc Netw. 2020;18(4):452-478.

80. Massarweh SA, Sledge GW, Miller DP, McCullough D, Petkov VI, Shak S. Molecular characterization and mortality from breast cancer in men. J Clin Oncol. 2018;36(14):1396-1404.

81. Wang F, Reid S, Zheng W, Pal T, Meszoely I, Mayer IA, Bailey CE, et al. Sex disparity observed for oncotype DX Breast recurrence score in predicting mortality among patients with early stage ER-Positive breast cancer. Clin Cancer Res. 2020;26(1):101-109. 